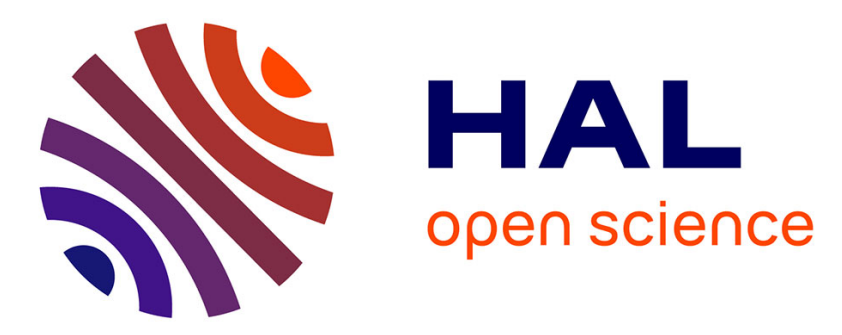

\title{
An assessment approach of maritime supply chain of energy vulnerability to piracy risk by simulation of spatial behavior
}

\author{
Martin Tanguy, Aldo Napoli
}

\section{- To cite this version:}

Martin Tanguy, Aldo Napoli. An assessment approach of maritime supply chain of energy vulnerability to piracy risk by simulation of spatial behavior. ESREL 2016, Sep 2016, Glasgow, United Kingdom. pp.ISBN 978-1-138-02997-2. hal-01417861

\section{HAL Id: hal-01417861}

https://hal-mines-paristech.archives-ouvertes.fr/hal-01417861

Submitted on 16 Dec 2016

HAL is a multi-disciplinary open access archive for the deposit and dissemination of scientific research documents, whether they are published or not. The documents may come from teaching and research institutions in France or abroad, or from public or private research centers.
L'archive ouverte pluridisciplinaire HAL, est destinée au dépôt et à la diffusion de documents scientifiques de niveau recherche, publiés ou non, émanant des établissements d'enseignement et de recherche français ou étrangers, des laboratoires publics ou privés. 


\title{
An assessment approach of maritime supply chain of energy vulnerability to piracy risk by simulation of spatial behavior
}

\author{
M. Tanguy \& A. Napoli \\ MINES ParisTech, PSL Research University, CRC - Centre for research on risks and crises, France
}

\begin{abstract}
Nowadays, oil tankers represent $25 \%$ of the targets of maritime piracy attacks. The main goal of this paper is to propose an approach to evaluate the vulnerability of the maritime supply chain to piracy risk. This approach, based on spatial reasoning and modelling tend to measure the impact of piracy on the network by the changes on maritime network realized by disruptions. To achieve it, we use multi-agent system, which can be defined by a set of agent within a shared environment. Agents are entity which has their own goal, capacity and resources which induce a specific behavior. By using the sum of these behaviors, the main objective of this paper is to measure disruptions by a conceptual approach to qualify and quantify the piracy risk.
\end{abstract}

\section{INTRODUCTION}

\subsection{Maritime network of energy}

The maritime supply chain of energy concerns all travels realized between ports on the maritime space. The use of this space has increase since 1970. This increase is due to the globalization which required a strong need of energy (Rodrigue et al, 2013). In $2007,62 \%$ of the petroleum was shipped by maritime transportation, as $27 \%$ of GNL, and $14 \%$ of coal. (Mérenne-Schoumaker, 2007). Main energy supply regions are located in Middle-East, Russia, Venezuela. They are linked by the maritime network of energy to major consumption regions which are North America, Europe and East Asia. This network is vital for the worldwide economy and used by oil tankers which link the different infrastructures (ports, refineries and offshore platforms) of the energy supply chain.

According to the 2014 annual report of IEA, Oil\&Gas represent more than an half of the worldwide energy demand. This demand tends to increase on the 2015-2035 period. Even if the part of fossil energy will decrease ( 82 to $76 \%$ ) the demand in Oil\&Gas will increase to 7027 Mt in 2012 at 8793 $\mathrm{mt}$ in 2035. Oil\&Gas is transported from production to consumption area by the energy supply chain. The supply can be resumed into three steps: extraction, transportation and consumption. Between the extraction and consumption, energy is transported by oil tankers within maritime space. Kaluza et al.(2010) study the maritime network by type of vessel and characterize for each type the network specificities. In the case of oil tankers, the number of vessels is lower than container ships and bulk dry carriers according to the AIS data set of the study. Second, an oil tanker changes their paths depending of the supply and demand in energy and are less predictable that container ships. Third, the network is more limited due to the fact they only transport energy and they link specific ports and refineries. The network also includes nodes inside the maritime space due to the presence of offshore platforms.

Maritime transportation knows many risks due to the specificity of maritime space. Elliott et al(2014) presents a typology of risks can meet the ships during transportation. These risks have different spatiotemporal features. For example, some risks are static, like reefs, but some are more complex and dynamic. Storms are dynamic and move through space but also have a dynamic shape due to many atmospheric causes. Piracy is a different type of risks due to the fact the dynamic of piracy is dependent of the dynamic of maritime traffic on network. In this paper, we focus on this specific risk and propose and approach to measure the impact of piracy on the maritime network. 


\subsection{Piracy at sea}

The International Maritime Organization (IMO) distinguishes two types of dangers at sea: safety and security. If security refer to risk relative to activates (e.g. storm, oil spill), safety refer to malevolent acts. It include terrorist attacks but also piracy risk. Maritime piracy is a major issue for the safety and security at sea, despite a decreased of attacks since 5 years, with 245 in 2010 and 445 in 2014 according to IMB in 2015. This trend is due to the improvement of controls at sea especially on Somalia coast (139 attacks in 2010 and 3 in 2014). But this trend should not hide those new risky zones increase for maritime transport like Indonesia and Malacca strait with 40 attacks in 2010 to 100 in 2014 . Due to these attacks, vessels can change their way to find safer maritime route.

There is several factors explaining the piracy is the contemporary era(Chalk, 2009) : the reduction of crew member by vessels for cost-cutting reasons, the political focus on homeland security more than international waters, the nonexistence of maritime police for all the maritime space, the corruption between some crew members and pirate, the anarchic situation in Somalia and the lack of sovereignty of some states and the pay of increasing sum of ransoms and the proliferation of arms into the world due to the conflicts. All of these factors eased the risk of piracy. This map illustrates (Figure 1) the maritime space use for transportation and the different area of piracy (Somalia Coast, Golf of Guinea, South East Asia and some specific ports in South America).

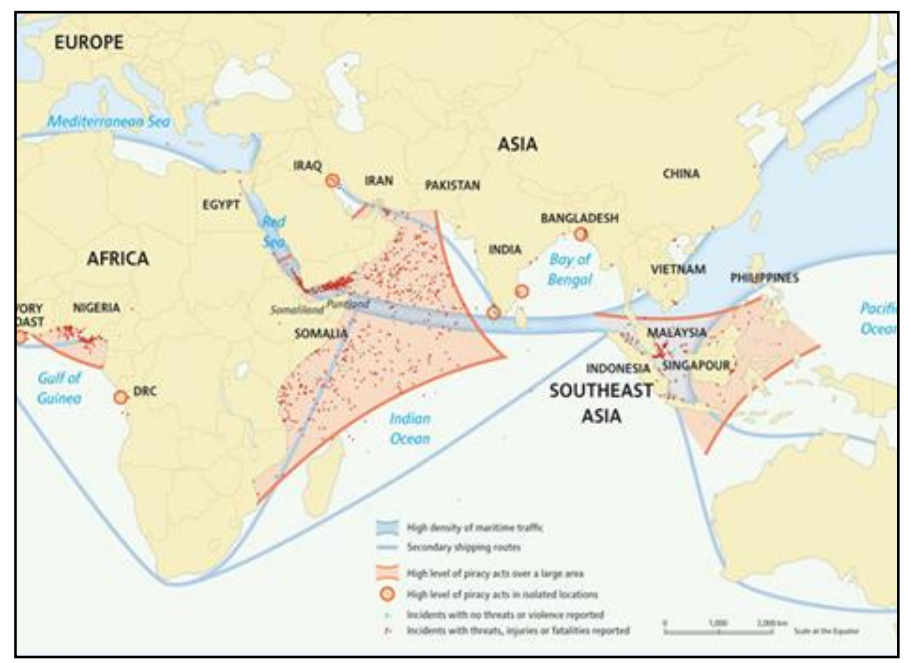

Figure 1. UNITAR Map of the Piracy zone and maritime network in Indian Ocean.

Piracy has an impact on maritime transport: first for lives of crewmember, with an important risk of death and injury, but also on economy. The annual cost of piracy for maritime transport is between 1 and 16 billions of dollars. Attacks on ships carrying energy represent a significant percentage. In 2006, they represent $12 \%$ of piracy attacks and more than $24 \%$ in 2007. (Bouejla et al. 2014). According to ICC IMB Piracy report this trend is stable with $25 \%$ of piracy attacks on oil tanker in 2014. There are several respond from governmental and industry to piracy which makes decrease the number of attacks, nay eradicate attacks, like in Somalia coast zone between 2010 and 2015.

This decrease is due to counter-measure like recommended transit corridors, transit by groups, escorted vessels, coordinated patrol and on-board security crewmembers (Vaněk et al. 2013). All these measures make decrease the piracy in the coast of Somalia and reduce the vulnerability of the maritime network of energy. Meanwhile, new risks zone can appear like in the Gulf of Guinea.

\subsection{Network modelling and disruptions}

These risks have an impact by causing disruptions on the network and produce an additionally cost for energy transportation, due to the additional time and distance needed to reach port of destination. Disruptions are defined by a loss of performance for a spatial structure to link different parts of the spatial structure (Zavitsas 2012). Loss of performance can be characterized by size, scale and time of the loss of accessibility which increase the vulnerability of the maritime network. Vulnerability can be defined as an impact, as the degree of degradation of the disruption, or as a capacity to respond and reorganize the spatial structure after the disruption (Veyret and Reghezza, 2005). Several approaches exist to study the vulnerability; all are related to the concept of accessibility which is the capacity of a location to be reached from another one (Rodrigue, 2013).

We aim to measure this cost by the use of spatial reasoning and modelling by an evaluation of piracy risk for energy transportation. Indeed, maritime space is a spatial mediator and its efficiency of is linked to accessibility (Gleyze 2005). To measure this accessibility, we tend to use the shortest paths and evaluate the accessibility for vessels depending of maritime barriers (e.g Reefs, mandatory zones, straits) and risks. This paper focuses on spatial modelling of piracy risks and proposes a conceptual approach to evaluate the impact of piracy risks on the maritime network of energy.

To achieve it, we use multi-agent paradigm which highlight the relationship between vessels and maritime space. Spatial constraints have an influence on vessels behaviors, and the sum of these behaviors allows us the measure the impact on maritime network during disruption (by deviation of vessels) and after, by the possible new configuration of network with a changed accessibility level. The figure below (Figure 2) describes our general framework. 


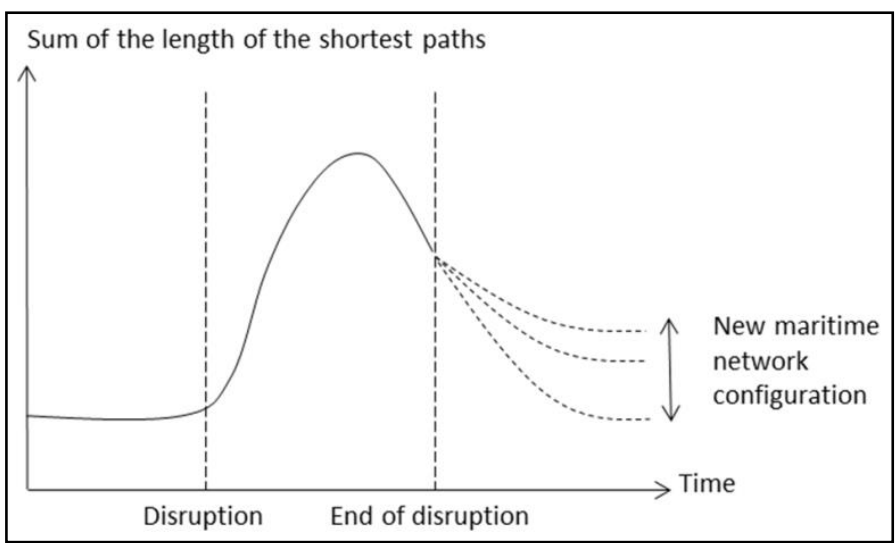

Figure 2. Impacts of disruptions on the accessibility of maritime network.

\section{STATE OF ART}

\subsection{Multi-agent modelling}

Agent-based modelling is a method of modelling and simulation where agents are modeled in a shared environment to interact each other's. They are used to find emerging behaviors and structures over simulations through the complexity of relationships existing between agents and environment. An agent is an entity which has its own goals and capacities in a shared environment (Ferber 1997). (Crooks and Heppenstall 2012) listed the different features of agent. First is autonomy, which means agents are autonomous units, able to take their own decision depending of the environment, the goal and capacity of the agent. Second is heterogeneity which means agents can have different attributes (e.g. age, nationality) which can induce different behavior. The third is active meaning they are an independent influence on the simulation. This makes some advantage for our problematic and the approach is able to capture emergent phenomena, providing a natural environment for the study and is particularity flexible for the relation in geographical model (Crooks and Heppenstall 2012).

The main goal of agent-based modelling is to model complex systems adopting a bottom-up approach by an individual-centric modelling. Ferber (1995) classifies multi-agent modelling in 3 categories: coexistence, cooperation and competition depending of the goa and capacity of agent as well as the resources of the environment.

Coexistence model need a same goal and capacity for agents and sufficient resources of environment. Cooperation model works when agents have same goal but resources or capacity of agents are limited, this category is used for congestion models or collaborative model. The last category, competition model are used in case of conflicted goal (E.g. predator-prey model). These different model are use for specific problems which is unable to solve with a

\subsection{Multi-agent and space}

Multi-agent systems are spatially explicit, agents have a location within the environment, and agentbased systems are particularity adapted for spatial modelling and simulation. For Pumain (2003) multiagent systems have 3 major assets in geography: the role of actors in the territories of transformations, on the place that take the representations in these processes and on the mechanisms of adaptation and speciation geographic features. Indeed, geography complexity helps to "understand the intervention of intermediate levels (emergence) between individual representations and the formation or maintenance of large social systems" (Daudé 2005).

Thus, the complexity helps to highlight "emerging mesogeographical structures" as well as a dynamic multi-scale, between the individual entities and comprehensiveness. To model in geographical agent-based (Langlois 2010) proposes a paradigm based on Agent/Organization/Behavior to study the relationship existing between social agents (vessels) and spatial agents (maritime space configurations). The main interest of this formalization is the differentiation between social agent and spatial agent. Social agents are used like any agent in agent-based systems and spatial agent are used for the localization of agents. This localization can influence the behavior of agent and agents can influence the spatial properties of the locations.

These localization agents are used to inform the location of agent within the shared environment. Three category of spatial structure can be distinguished for localization agents: regular structure (Langlois 2010)(e.g. square, hexagon.), non-topological irregular structure (e.g. points, lines and surface in a continuous space.), and irregular topological structure (e.g networks, Delauney triangulation.).

\subsection{Agent-based modelling and piracy}

Many case of multi-agent modelling exist in geography: in transportation, road and rail have been study since many years with multi-agent modelling, but study on maritime transport is quite limited (Vaněk et al. 2011). Nevertheless, Marchione and Johnson (2013) demonstrate that at a macro level, incident of piracy is clustered into the maritime space and thus, the importance of space for the safety at sea.

(Jakob et al. 2012) propose a model to the optimization of fight for the risks of piracy, by a competition agent-based modelling for merchant vessel, piracy vessel and army vessel and test several solutions to piracy attack. Maritime space is model according of two characteristics: bathymetry and weather. They used a continuous space modelling where vessels move depending of an origin/destination matrix. Geography and bathymetry take account of the possi- 
bilities of move and weather as a factor on speed for vessels.

If the system doesn't take account of the constraints of space, the results of their study are interesting and show the consequences on the counter-measures on piracy attacks. The study concludes that the most accurate answer to attack according to the simulation is to increase the number of navy vessels into restricted corridors. The IRTC (International Recommended Transit Corridor) establish in 2009 demonstrate the efficacy of this measure to decrease the number of attacks.

\section{APPROACH PROPOSED}

As seen before, we consider in our work the maritime network of energy as the sum of the trips made by vessels. Multi-agent modelling allows us to understand the vulnerability at a global scale by the behavior of each vessel depending of their objective and capacity. Its objective can be resumed in their environment by accessibility to evaluate the impact of disruptions on the maritime network.

In this paper, we propose an approach to measure the impact of risky area by the accessibility of space. We don't aim to model the piracy ships but we tend to simulate the influence of piracy risk on the maritime network and assess its impact.

\subsection{Modelling objectives}

The first objective of the modeling approach is to define a level of accessibility for each point of the maritime area. Accessibility is a relative concept, this level of accessibility is related to several factors: geographic, economic, but also safety. The second objective is to describe individual behaviors related to accessibility levels of maritime space. These behaviors are described in two stages: first, choosing a travel destination from a starting point in the network. Third, this method aimed to assess the vulnerability in a context of piracy risk, the goal is to simulate space-time disturbances to test the influence of these on the maritime energy network. Finally, the last objective of this method is to evaluate through indicators vulnerability of maritime network through different spatial behavior of ships and function disturbances scenarios in the maritime space.

\subsection{An agent-based approach}

We choice multi-agent modelling and simulation in our work for several reasons: first, we consider the maritime network as the result of the sum of all the paths. Second, we consider multi-agent modelling handle to detect the friction of space caused by disruptions. Third, these disruptions can make emerge new paths and network configuration into the maritime network.

We consider the maritime network like a spatial network, with topological property (degree distribution, clustering) but also geometrical properties by taking account of distance between the different nodes of the graph.

The model is composed of three different elements in interactions: the ports and offshore structure, the maritime space used for transportation and the vessel which are agent with a spatial behavior. These elements are describe in the following table :

Table 1. Elements of the model

\begin{tabular}{ll}
\hline Element of the model & Properties \\
\hline Ports/Offshore platform & $\begin{array}{l}\text { Location of origins and destina- } \\
\text { tions of the maritime network with } \\
\text { demand and/or supply of energy }\end{array}$ \\
Space & $\begin{array}{l}\text { Gridded space subdivided by cells } \\
\text { with an accessibility level }\end{array}$ \\
Vessel & $\begin{array}{l}\text { Agent which transport a quantity } \\
\text { of energy within the maritime } \\
\text { space }\end{array}$ \\
\hline
\end{tabular}

1. Ports/Offshore elements :

They correspond to the different locations of the maritime network. Each port has its own demand and/or supply and a gravity model can be used to identify the trips to realize. If the trip is necessary, a vessel is created which a quantity of energy from the supply location to the demand location.

2. Spatial elements :

The maritime space corresponds to the distance to cross between the origin and destination. The space is divided into cells which have all an accessibility rate. The accessibility level depends of the distance but also to the friction link to the elements of maritime space. Piracy is a friction which induces losses of accessibility.

\section{Vessel elements :}

Vessels are agent with the goal to transport an amount of energy to a destination. Vessels have a spatial behavior link to their goal, capacity and environment (maritime space). These spatial behaviors form a trip between ports and thus a link between two locations. The sum of the trips forms the maritime supply chain of energy.

\subsection{Spatial modelling, distance and accessibility}

In our case of study, maritime network isn't restricted to an infrastructure like road and rail network. (Rodrigue,2013). Nevertheless, if maritime space is a mostly free space, several level of accessibility explains the shape of maritime network.

To represent the space, we use a squared grid who provide for each cell of space topological and geo- 
metric information. For the spatial behavior of vessels, we use Euclidian distance into the spatial modelling to find the shortest path according to the accessibility level. The accessibility level corresponds to the relative ease to access a place in space comparing to the neighbors place. This accessibility level depends of several factors:

(1) Ports and platform proximity matrix: Accessibility is measured by the Euclidian distance to the port. A shortest path between two ports is the sum of the accessibility between two locations. (Figure 3 )

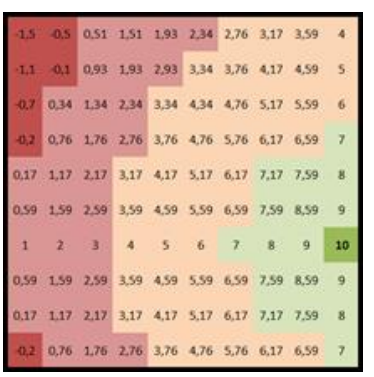

Figure 3. Accessibility matrix from a specific location

(2) Piracy risk matrix: For each travel of energy, we check the distance of the trips to insecure coast. This makes decrease the accessibility of cells. Each constraint has an impact of accessibility. Elements of space are classified depending of the friction of space they produce. In the case of piracy, the risk increases as it is near the insecure coast (Figure 4).

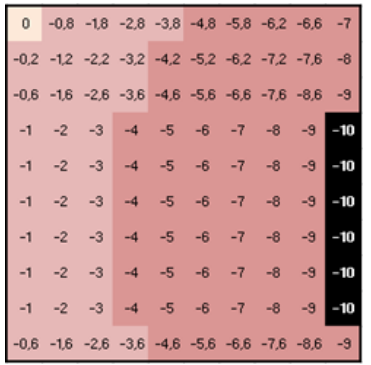

Figure 4. Accessibility losses due to the piracy zone

(3) Visited path matrix: As seen before, Vanek et al (2012) conclude that corridors into maritime network decrease the risk of attack due to the reduction of space where surveillance is needed. Thus, maritime network tend to be clustered by most visited paths to reduce the vulnerability (Figure 5).

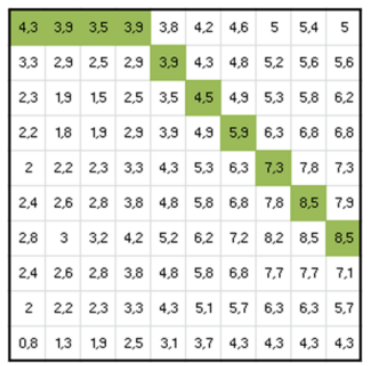

Figure 5. Accessibility due to the already visited paths
The total accessibility of each cell is the sum of the three matrixes. These matrixes are dynamic, and depend of the supply and demand of locations, evolution of piracy zones and ever realized trips over the maritime. In our case, three matrixes are needed for the accessibility modelling, but more matrixes can be added depending of the case of study (Figure 6).

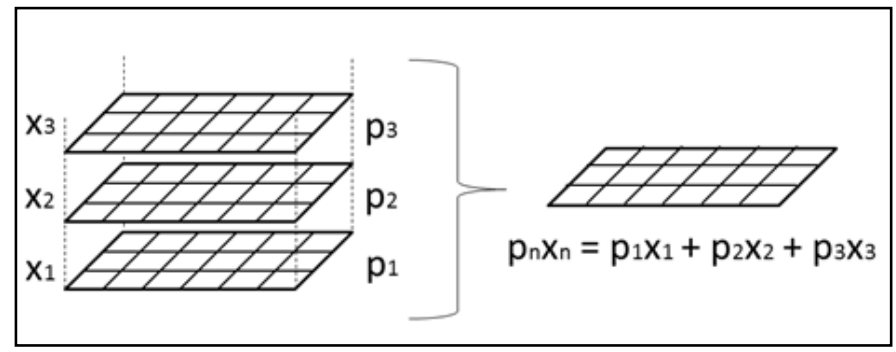

Figure 6. Overall accessibility matrix

The overall accessibility is equal of the sum of all accessibility and their relative weight and can be describe under the formula $p_{n} x n$ where $x$ represent a matrix, $p$ the weight of the matrix and $n$ the number of matrixes. This accessibility is used by vessels to transport the energy and the main factor of the spatial behavior of vessels.

\subsection{Spatial behavior modelling}

The accessibility matrix is use in a second time to determine the spatial behavior of vessels. A spatial behavior can be defined by a goal (a location to reach) and a capacity to reach this destination (e.g. ports, offshore platform) by means of the accessibility matrix.

However, several method of distance can be used for vessels spatial behavior. The first one is topological distance(Figure 7), based on the number of cells a vessel has to cross through the spatial modeling to reach the goal of destination. The agent moves among the eight adjacent squares depending on the lowest topological distance. The topological distance corresponds to the number of moves to reach a place.

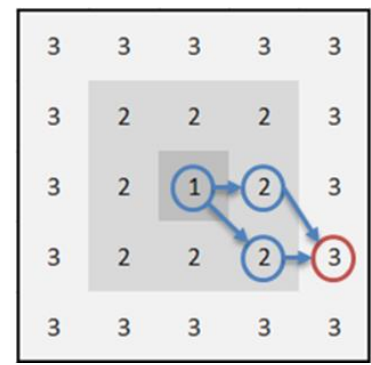

Figure 7. Topological distance

The topological distance can be used for the most basic spatial behavior but can't account of the constraints of space. To solve it, spatial behavior has to take account of accessibility level. Two types of dis- 
tance corrected by weigh is possible: absolute and relative.

The first one, absolute weighted distance (Figure 8) correspond to the path with the best accessibility overall, taking account of the sum of all the locations crossed within the accessibility matrix. For a vessel, this means to choice the most accessible path between its actual position in the matrix and the destination to reach.

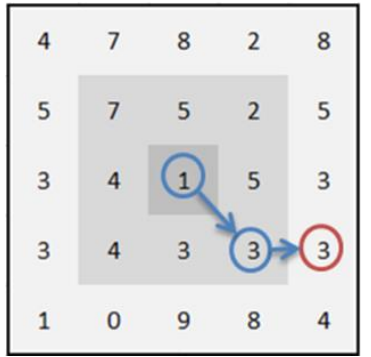

Figure 8. Absolute distance

In the second case, weighted relative distance (Figure 9), paths are building depending of the average accessibility of the paths within the accessibility matrix. For a vessel, this means to choice the most accessible neighbor for each step of travel.

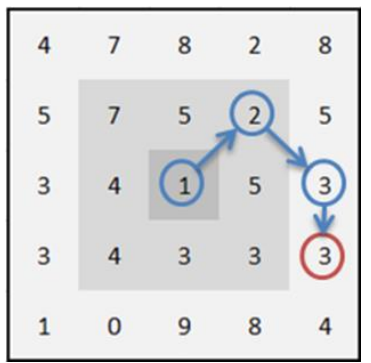

Figure 9. Relative distance

Each distance can be used for the vessel to build its spatial behavior. In this table, a comparison of distance form our example is made by several indicators. $T$ represent the topological distance or the number of moves within the matrix, $M A$ the average accessibility of the location of the matrix crossed and $O A$ the sum of the accessibility of the path.

Table 2. Comparison of the different distance

\begin{tabular}{llll}
\hline Distance type & $T$ & $M A$ & $O A$ \\
\hline Topological distance & 2 & - & - \\
Weighted absolute distance & 2 & 2.33 & 7 \\
Weighted relative distance & 3 & 2.25 & 9
\end{tabular}

The selection of distance for the spatial behavior depends of the vessel capacity and the environment. Indeed, theses distances are specific and measure different possibilities of move. The first one, topological distance measure the spatial shortest path due to the fact we use Euclidien distance in the matrix (This doesn't works in case of Von Numann or Moore distance). The second, weighted absolute distance, is used to taking account the effect of accessi- bility of space on the spatial behavior and measure the temporal shortest path. The last one, weighted relative distance can be use of case of unpredictable case like disruption and measure the temporal shortest path in case of modification of accessibility within maritime space. The figure below (Figure 10) represents the different distance, their relationship and the associate measurement.

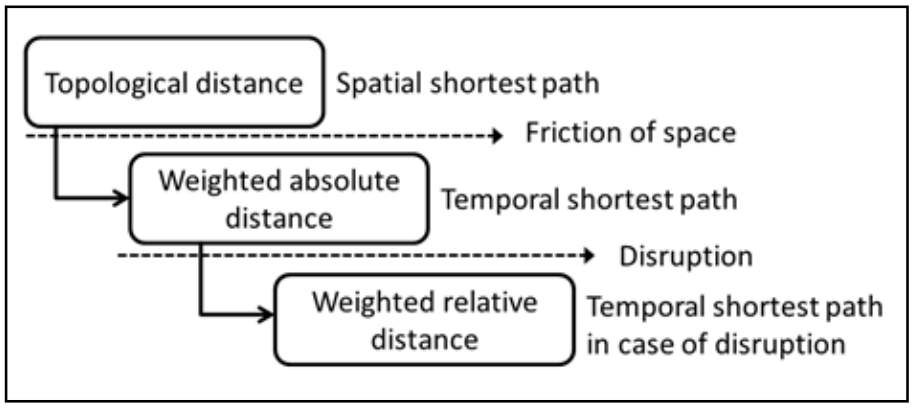

Figure 10. Distance and associated shortest paths

\subsection{Simulation on NetLogo}

To create and test our model, we choice NetLogo which is a multi-agent modelling and simulation platform. NetLogo works with Logo language and is a platform use for the exploration of emergent phenomena.

We took a simple example to illustrate our problematic. A number of ports and offshore platforms are connected by vessels which draw a transportation network by the number of trips realize by zone (squared cells). At each iteration in the simulation, vessels move forward their goal destination depending of the accessibility for one cell. Accessibility is function of the shortest distance and visited paths and cannot cross piracy impacted zone in orange. Vessels use the spatial and gather quickly into paths forming a maritime network.

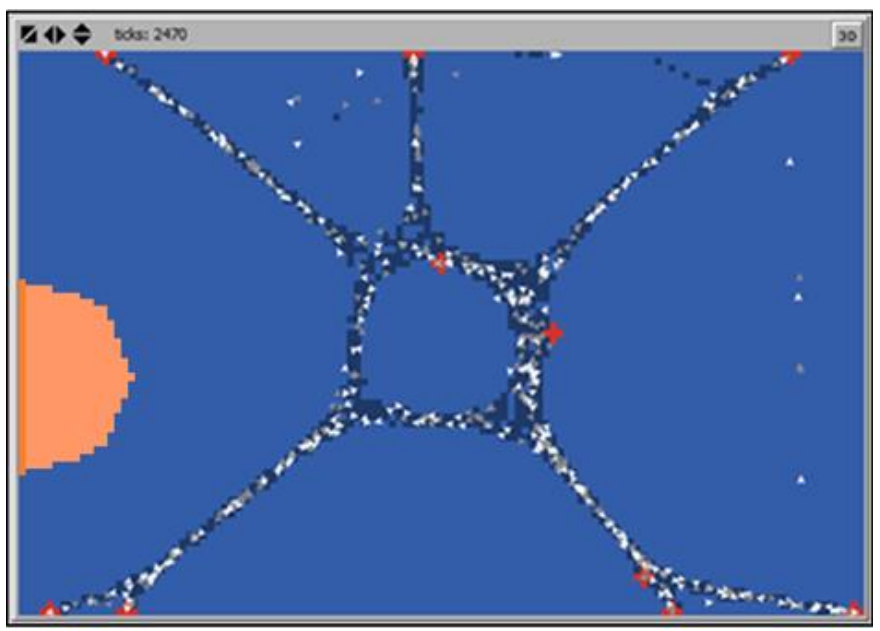

Figure 11. Random maritime network simulation at 2470 iteration (NetLogo)

At 2470 iterations (Figure 11), the network forms a great circle at the center which links the different 
part of the network. The network avoids the piracy area on the maritime space.

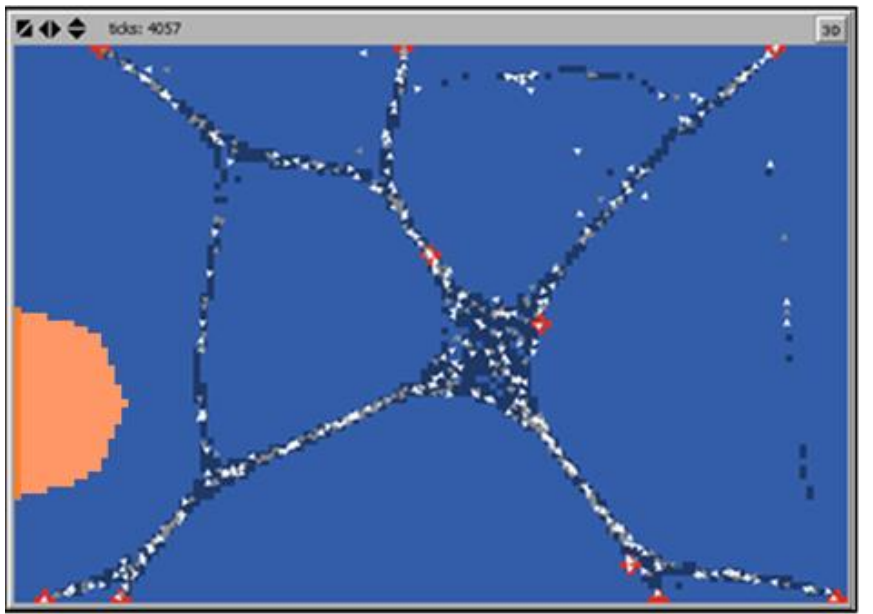

Figure 12. Random maritime network simulation at 4057 iteration (NetLogo)

At 4057 iterations (Figure 12) emerge a new path on the left of the network. This is due to the gathering of the vessels in the center of the network. This gathering induces new spatial behaviors to reach ports on the left and create a new link within the network. This configuration increases the risk of piracy due to the proximity with impacted piracy area. This emerging phenomenon demonstrates the interest in the use of multi-agent systems.

This example illustrates the influence of accessibility over the spatial properties of maritime network. We tend to measure the impact of piracy by adding an accessibility level due to the presence of piracy risks.

\subsection{Evaluation of disruption due to piracy risk}

The sum of these spatial behaviors forms the maritime network and especially the maritime supply chain of energy for the oil tanker. These spatial behaviors take account of accessibility level in space. The evaluation of vulnerability can be done by the evolution of shortest paths between the ports of the network. Indeed, vessels moves among the eight adjacent squares depending of accessibility rate to reach their own goal. The increase of shortest paths is an indirect impact of accessibility losses. Several measurements are possible for the measure of impact of disruptions.

The first measure of vulnerability is the shortest path evolution within space. Indeed, accessibility can increase the distance between two ports due to the additional distance due to the disruption. The global disruption impact can be measured by the sum of the shortest paths before and after the disruption.

The second measure is the shortest path in time: accessibility can also increase the temporal duration for reach a port form another one. The global disrup- tion impact can be measured by the sum of the shortest paths before and after the disruption.

Finally, the last measure is cost. From the losses of temporal and spatial distance, the cost of transportation can be measure (fuel, decrease of energy delivered by the maritime network) and link to accessibility.

\section{FURTHER WORKS AND CONCLUSION}

All of these measures would be used for quantify and qualify the vulnerability of the maritime network of energy. We tend to test the proposed model and measure the effect of piracy on the global maritime network of energy. To enhance the model we have first to specify the dynamic of piracy risk, like the presence of mother ship used by pirates to enlarge piracy area.

After this improvement, we aim to test our system on real geographical area and test the impact of piracy within several ocean and sea. Indeed, as seen before, piracy zone constantly appear and disappear due to geopolitical and economic factors. Multiagent modelling may help to understand this impact and are particularity adapted to transportation vulnerability study. By the study of impact of disruption on network, we can observe the evolution of the maritime network thought different structures emerging of the evolution of accessibility within maritime space.

This issue is crucial for the economy and especially energy. To discover new spatial knowledge on the transportation of energy may bring new highlights on maritime network vulnerability. Nevertheless, our approach tends to be generic and we aim to test several type of scenario of disruptions on the maritime network (E.g. storms, oil spill, and canal closure).

\section{REFERENCES}

Bouejla, A, X. Chaze, F. Guarnieri, and A. Napoli 2014 A Bayesian Network to Manage Risks of Maritime Piracy against Offshore Oil Fields. Safety Science 68: 222-230.

Chalk, P. (2009). Maritime piracy: Reasons, dangers and solutions (No. RAND-CT-317). RAND CORP SANTA MONICA CA.

Crooks, Andrew T., and Alison J. Heppenstall 2012 Introduction to Agent-Based Modelling. In Agent-Based Models of Geographical Systems. Alison J. Heppenstall, Andrew T. Crooks, Linda M. See, and Michael Batty, eds. Pp. 85-105. Dordrecht: Springer

Daudé E 2005 Systèmes Multi-Agents Pour La Simulation En Géographie: Vers Une Géographie Artificielle. Modélisation En Géographie: Déterminismes et Complexités(chap. 13): 353-380.

Elliott M, N. D. Cutts, and A Trono 2014 A Typology of Marine and Estuarine Hazards and Risks as Vectors of Change: A Review for Vulnerable Coasts and Their Management. Ocean \& Coastal Management 93: 88-99. 
Ferber, J, 1997 Les Systèmes Multi-Agents: Un Aperçu Général. Techniques et Sciences Informatiques 16(8). http://www.researchgate.net/profile/Jacques_Ferber/publica tion/242623967_Les_systemes_multi-

agents_un_aperu_general/links/5409e5100cf2df04e7491c 02.pdf, accessed October 27, 2015.

Gleyze, J-F 2005

La Vulnérabilité Structurelle Des Réseaux de Transport Dans Un Contexte de Risques.

Jakob M, O. Vaněk, O. Hrstka, and M. Pěchouček 2012

Agents vs. Pirates: Multi-Agent Simulation and Optimization to Fight Maritime Piracy. In Proceedings of the 11th International Conference on Autonomous Agents and Multiagent Systems-Volume 1 Pp. 37-44. International Foundation for Autonomous Agents and Multiagent Systems. http://dl.acm.org/citation.cfm?id=2343581, accessed April 4, 2016.

Kaluza, P., A. Kolzsch, M. T. Gastner, and B. Blasius 2010 The Complex Network of Global Cargo Ship Movements. Journal of The Royal Society Interface 7(48): 1093-1103.

Langlois, Patrice 2010Simulation des systèmes complexes en géographie. Paris: Hermes science publ. : Lavoisier.

Marchione, E., and S. D. Johnson 2013 Spatial, Temporal and Spatio-Temporal Patterns of Maritime Piracy. Journal of Research in Crime and Delinquency 50(4): 504-524.

Mérenne-Schoumaker, Bernadette, and Bernadette MérenneSchoumaker 2007 Géographie de l'énergie: acteurs, lieux, enjeux. Paris: Belin.

Pumain, D 2003 Une approche de la complexité en géographie. Géocarrefour 78(1): 25-31.

Rodrigue, J-P, C Comtois, and B Slack, eds. 2013 The Geography of Transport Systems. 3. ed. London: Routledge.

Vaněk, O, M Jakob, O Hrstka, and Michal Pěchouček 2011Using Multi-Agent Simulation to Improve the Security of Maritime Transit. In Multi-Agent-Based Simulation XII Pp. 44-58.

Springer. http://link.springer.com/chapter/10.1007/978-3-642-284007_4, accessed February 4, 2016. 2013 Agent-Based Model of Maritime Traffic in Piracy-Affected Waters. Transportation Research Part C: Emerging Technologies 36: 157-176.

Veyret, Y, and M Reghezza 2005 Aléas et Risques Dans L'analyse Géographique. Annales Des Mines: p. 61-89

Zavitsas, Kostas, 2012 The Vulnerability of the Petroleum Supply Chain 